\title{
Influence of Magnet and Flux-Barrier Arrange- ment on Flux Control Characteristics of Hybrid Excited ECPMS-Machine
}

\author{
Piotr Paplicki ${ }^{1}$ \\ ${ }^{I}$ Department of Power Systems and Electrical Drives, West Pomeranian University of Technology \\ Szczecin, \\ Sikorskiego 37, 70-313 Szczecin, Poland \\ paplicki@zut.edu.pl
}

\begin{abstract}
In this paper, novel rotor design concepts for a synchronous machine with hybrid excitation are presented. The influence of a magnet and a flux-barrier arrangement on field weakening and strengthening characteristics obtained by 3D FEA prediction of an ECPMS (Electrically Controlled Permanent Magnet Excited Synchronous) machine is estimated. Finally, 3D-FEA and experimental results of a field control characteristic and no-load back electromotive force (backEMF) waveforms of the machine with new prototype rotor design are examined.
\end{abstract}

Index Terms-Electric vehicles; experimental results; permanent magnet machines; hybrid excitation; field-weakening; flux control.

\section{INTRODUCTION}

It has been indicated that hybrid excited (HE) machines have attractive features for variable-speed generator applications or drive applications where a constant-voltage operation over a wide range of speeds is particularly required. Due to an additional field excitation winding placed on the stator or rotor of HE machine a wide range of the stator flux linkage can be effectively achieved. There are numerous HE machine types developed to use in electric vehicle applications, mainly due to their field-weakening features and potentially good drive performance [1]-[12].

In this paper three different rotor magnetic structures for design purpose are developed for the ECPMS machine (Fig. 1) which has been presented and widely tested earlier [12]-[14]. Furthermore, an optimization procedure and method of arrangement of PMs and forming the iron pole and PM pole shapes in order to extend the field-weakening capability and reduce the cogging torque of the machine, have been proposed earlier [15]-[18].

To evaluate machine designs based on new rotor structures, three dimensional finite-element analyses (3D FEA) have been performed using the Flux3D v.10.4 software package by Cedrat, Ltd. Finally, an ECPMS machine prototype with selected one novel rotor design, has been built and initially tested.

Manuscript received 25 March, 2016; accepted 7 February, 2017.

This research was funded by a grant (No. 2015/17/B/ST8/03251) from the National Science Centre, Poland.
Control of PM-excitation in the presented machine is implemented by the additional field excitation winding, which is shown on the Fig. 1 as DC control coil. It allows to adjust the stator flux linkage in required range by adequate control of the DC control coil current $I_{\mathrm{DC}}$.

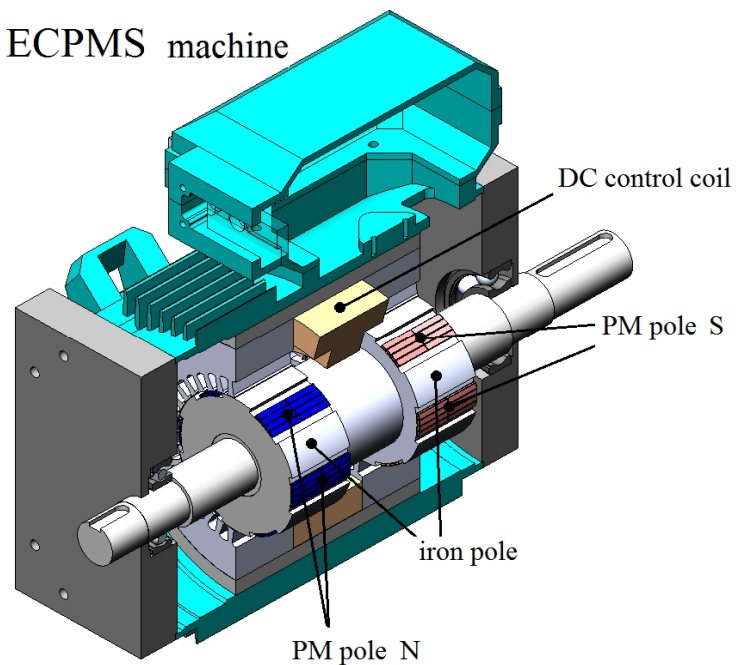

Fig. 1. Hybrid excited ECPMS-machine.

The machine produces electromagnetic torque $T_{e}$ from its PM flux $\Psi_{\mathrm{PM}}$ and from optionally additional field excitation flux $\Psi_{\mathrm{DC}}$, and reluctance torque $T_{\text {rel }}$ from their rotor saliency $\xi$ written as

$$
\xi=L_{q} / L_{d}
$$

where $L_{q}, L_{d}-q$ - and $d$-axis stator inductances.

The reluctance torque is formed by the number, location and thickness of rotor flux barriers (FBs). The PM flux can be controlled independently of the reluctance torque by varying the magnet remanent flux density and the fraction of the rotor barriers. The additional field excitation flux is excited by the DC control coil current. Hence, the electromagnetic torque of the ECPMS machine can be written as

$$
T_{e}=\frac{3}{2} p\left(\Psi_{P M} I_{q}+M_{\mathrm{DC}} I_{\mathrm{DC}} I_{q}+L_{d}(1-\xi) I_{d} I_{q}\right)
$$


where $I_{q}, I_{d}-q$ - and $d$-axis current components respectively, $M_{\mathrm{DC}}-\mathrm{DC}$ control coil mutual inductance.

It should be noted that a field-weakening range limitation of the machine determines a pure boundary condition. Fieldweakening requirements generally impose a limit on the peak line back-EMF at maximum speed. At no-load operation, an infinite speed of the machine can be found if the control coil current entirely removes the stator flux linkage. Based on a parallel drive and traction machine performance, the maximum speed of the machine is accepted from three to four times the rated speed. Hence, the stator flux linkage at this speed must be also decreased three times at least. To achieve such a flux level in no-load operation, an optimal rotor structure with effective field-weakening capabilities can be found. Moreover, in this kind of machines as low mass and active material volume as possible is also required. Hence, it is not an easy task to form a satisfying rotor design for the ECPMS-machine with ensuring the field-weakening and good efficiency for all speeds of the machine.

\section{NEW CONCEPTS OF INTERIOR PM AND FB MACHINE TOPOLOGIES FOR ECPMS MACHINE}

According to results earlier presented in [14], [19] the effectiveness in adjusting fluxes passed through the iron pole section by the additional field excitation winding (by using the DC control coil) of the ECPMS-machine is very crucial for the field-weakening. Hence, during the development of rotor designs much attention have been paid to flux-barrier geometries and their location.

Figure 2 shows three novel concepts of rotor magnetic structure topologies for the ECPMS machine with a unique multiple flux-barrier arrangement and the different quantities of PM material.

There are four types of flux barrier used in the concepts: a Single Flux Barrier (SFB) type which is filled only over PM poles of the rotor; an Embedded Flux Barrier (EFB) type which is located inside the rotor laminations; a Radial Flux Barrier (RFB) type which is radially formed inside the rotor magnetic structure; an Open Flux Barrier (OFB) type centrally formed in PM poles of the rotor.

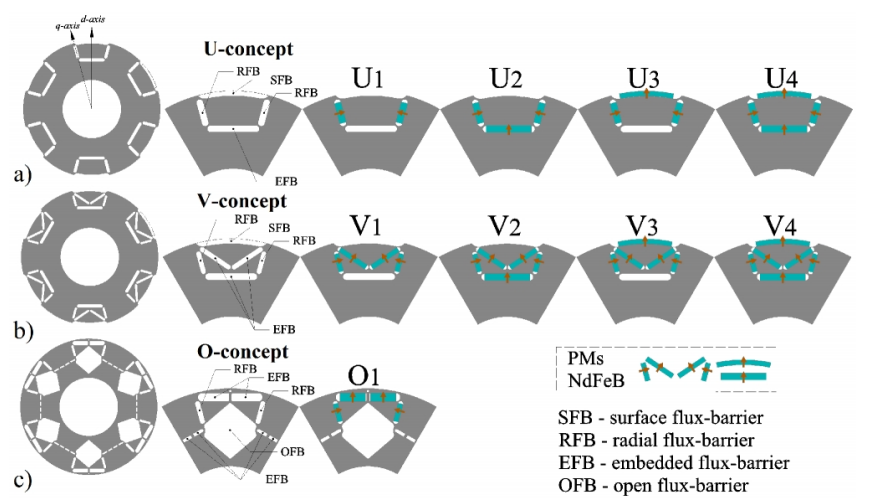

Fig. 2. Novel concepts of rotor structure design for the ECPMS-machine.

Figure 2(a) shows the U-topology concept which is formed by four multiple flux barrier arrangement containing single SFB and EFB barrier with two RFBs per PM pole of the rotor.

In the $\mathrm{U}_{1}$ concept there are two PMs located inside the
RFBs.

The $\mathrm{U}_{2}$ concept contains one additional PM which is locked in the EFB. $\mathrm{U}_{3}$ concept takes additional PM but it is surface mounted in the EFB. In the $\mathrm{U}_{4}$ concept there are four PMs located inside all flux barriers.

In Fig. 2(b) the V-topology concept is shown which has two additional V-shaped EFBs formed inside the PM pole of the rotor. Other barriers are formed similarly to the Utechnology concept. In the $\mathrm{V}_{1}$ concept there are four PMs located inside the RFBs and two v-shaped EFBs. The $\mathrm{V}_{2}$ concept contains one additional PM which is locked in the EFB. The $\mathrm{U}_{3}$ concept takes an additional PM but it is surface mounted in the EFB. In the $\mathrm{V}_{4}$ concept there are six PMs located in all flux barriers.

Figure 2(c) shows the O-topology concept which is formed by eight multiple flux barrier arrangement. Inside the lamination there are four EFBs, two RFBs and a single OFB per $\mathrm{PM}$ pole of the rotor. In the $\mathrm{O}_{1}$ concept four PMs are placed inside the RFBs and the EFBs located the nearest air gap surface of the machine.

\section{INFLUENCE OF MAGNET AND FLUX BARRIER ARRANGEMENT ON ECPMS-MACHINE FLUX-WEAKENING}

Figure 3 shows a no-load 2-D air-gap flux density distribution in the $\mathrm{U}$ and $\mathrm{V}$ concepts at two different field excitation levels: field-weakening at $I_{\mathrm{DC}}=5.0 \mathrm{~A}$ and at field without additional excitation at $I_{\mathrm{DC}}=0$. As can be seen in the figure, an amplitude of air-gap flux density waveforms for all models varies and it is strongly depended on quantity of magneto-motive force (MMF) sources of the machine, and therefore it depends on the saturation. Moreover, presented results show that increasing flux crossing the airgap over the iron pole section is particularly shown in the $U_{1}$ and $\mathrm{V}_{2}$ concepts where the proportion of the magnets is the smallest. That means, there is an optimum arrangement of magnets and flux-barriers for presented rotor structures to obtain required field-weakening range of the machine. In general, it can be concluded that a compromise between the power density requirement and the field-weakening performance of the ECPMS-machine has to be made.

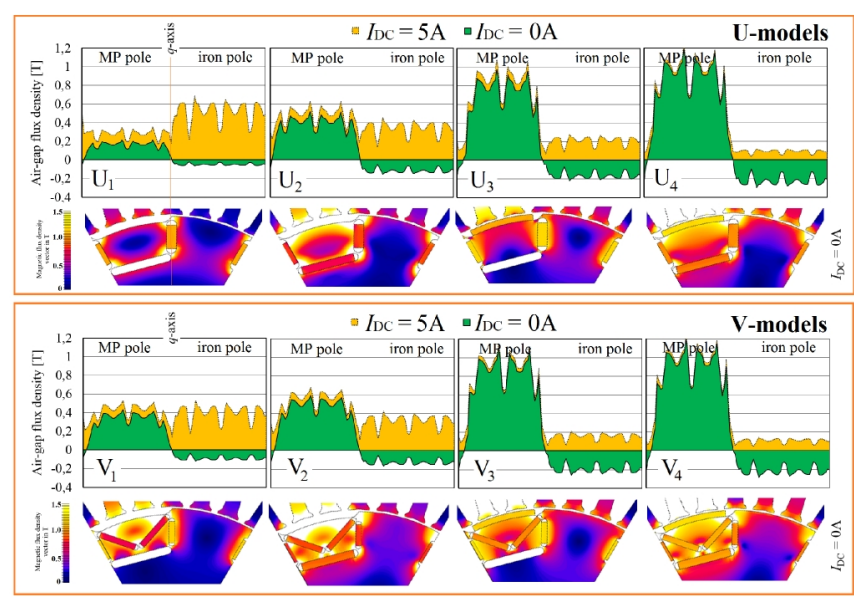

Fig. 3. No-load magnetic flux density distribution over magnet pole and iron pole pitch of the $\mathrm{U}_{1}-\mathrm{U}_{4}$ and $\mathrm{V}_{1}-\mathrm{V}_{4}$ concepts.

A comparison of machine parameters obtained by 3DFEA predictions for all models as: PM fluxes $\Psi_{\mathrm{PM}}$ FEA, $d$ axis stator inductances $L_{d_{-} \mathrm{FEA}}$, the rotor saliency ratio $\xi$ as a 
ratio $L_{q_{-} \mathrm{FEA}} / L_{d_{-} \mathrm{FEA}}$ and maximum value of electromagnetic torque $T_{e_{-} \text {max }}$ FEA achieved at nominal stator currant $I_{s \mathrm{~N}}=$ $30 \mathrm{~A}$ and $I_{\mathrm{DC}}=0$ was carried out. Moreover, according to (2) and FEA results a relative reluctance torque $T_{\text {rel }} \max \%$ as a maximum value of reluctance torque $T_{r e l}$ expressed as percentage to $T_{e_{-} \text {max_FEA }}$ has been evaluated. Similarly, according to FEA results a relative cogging torque $T_{\text {cogg_max_FEA } \%}$ as a maximum value of cogging torque $T_{\text {cogg_max_FEA }}$ expressed as percentage to $T_{e_{-} \text {max_FEA }}$ achieved at no-load stator currant $I_{s}=0$ and $I_{\mathrm{DC}}=0$ has been also estimated and recorded in Table I.

TABLE I. MACHINE PARAMETERS.

\begin{tabular}{|c|c|c|c|c|c|c|c|c|c|c|}
\hline & & $\mathbf{U 1}$ & $\mathbf{U} 2$ & $\mathbf{U 3}$ & $\mathbf{U 4}$ & $\mathbf{V 1}$ & $\mathbf{V 2}$ & $\mathbf{V 3}$ & $\mathbf{V 4}$ & O1 \\
\hline$\Psi_{\text {PM_FEA }}$ & $\mathrm{mWb}$ & 63.9 & 153.7 & 225.6 & 303.4 & 122.4 & 169.8 & 267.8 & 296.5 & 232.5 \\
\hline$L_{d \_ \text {FEA }}$ & $\mathrm{mH}$ & 4.4 & 4.3 & 4.5 & 3.9 & 4.3 & 4.3 & 4.1 & 3.9 & 3.9 \\
\hline$\xi$ & - & 1.23 & 1.22 & 1.18 & 1.23 & 1.25 & 1.25 & 1.23 & 1.26 & 1.54 \\
\hline$T_{e_{-} \text {max_FEA }}$ & $\mathrm{Nm}$ & 18.8 & 42.2 & 61.3 & 81.9 & 34.1 & 46.7 & 72.3 & 80.5 & 56.5 \\
\hline$T_{\text {rel_max} \%}$ & $\%$ & 21.9 & 9.2 & 5.3 & 4.5 & 13.0 & 9.5 & 5.2 & 5.2 & 13.4 \\
\hline$T_{\text {cogg_max_FEA } \%}$ & $\%$ & 2.2 & 5.4 & 17.6 & 27.7 & 4.5 & 6.1 & 22.2 & 28.8 & 11.3 \\
\hline
\end{tabular}

Presented results show that, firstly, the reluctance torque in the $\mathrm{U}_{1}, \mathrm{~V}_{1}, \mathrm{O}_{1}$ concepts considerably affects the electromagnetic torque maximum value and it can be used to extend machine torque or constant-power speed range by $d$ axis stator current injection. Secondly, the relative cogging torque value up to $5 \%$, as the value required, is achieved only in the $\mathrm{U}_{1}, \mathrm{~V}_{1}$ concepts. Thirdly, at nominal stator currant condition the $T_{e_{-} \text {max_FEA }}$ above $30 \mathrm{Nm}$, as in this case the value required, is obtained in the $\mathrm{U}_{2-4}, \mathrm{~V}_{1-4}$, and $\mathrm{O}_{1}$ concepts. Fourthly, the best rotor saliency equal to 1.54 is observed in the $\mathrm{O}_{1}$ concept.

Taking into account the results of performed computations and a feasibility of the rotor design it has been decided that in this publication more attention is paid to the $\mathrm{U}$ and $\mathrm{V}$ concepts.

In order to ensure the effectiveness of an air-gap field control of the machine in the $\mathrm{U}$ and $\mathrm{V}$ concepts, FEA predictions of the back-EMF waveforms at different values of the control coil current $I_{\mathrm{DC}}$ have been carried out.

Figure 4 shows the back-EMF waveforms induced in the phase stator windings at $1000 \mathrm{rpm}$ constant speed and at $I_{\mathrm{DC}}$ adjusted in the range $-5 \mathrm{~A}$ to $5 \mathrm{~A}$.

Based on the obtained results, a no-load output terminal voltage $E_{0}$ versus $I_{\mathrm{DC}}$ characteristic has been investigated and presented in Fig. 5.

Additionally, Table II shows results of back-EMF values obtained by FEA for $\mathrm{U}_{2-4}$ and $\mathrm{V}_{1-4}$ concepts in comparison with experimental results performed on a prototype (ECPMSM V1), where: $E_{0}$ denotes no-load output terminal voltage rms value obtained at $I_{\mathrm{DC}}=0$; maximum $E_{\max }$ and minimum $E_{\min }$ stand for voltage values on the characteristics $E_{0}$ vs. $I_{\text {DC }}$ (Fig. 5) and voltage ratios: $E_{\max } / E_{\min }$ and $E_{0} / E_{\min }$.

TABLE II. FEA PREDICTIONS AND EXPERIMENTAL RESULTS OF NO-LOAD BACK- EMF VALUES.

\begin{tabular}{|c|c|c|c|c|c|c|}
\hline \multirow{4}{*}{$\begin{array}{c}\text { FEA } \\
\text { predictions }\end{array}$} & concept & $\boldsymbol{E}_{\mathbf{0}}$ & $\boldsymbol{E}_{\mathbf{m a x}}$ & $\boldsymbol{E}_{\min }$ & $\boldsymbol{E}_{\mathbf{m a x}} / \boldsymbol{E}_{\min }$ & $\boldsymbol{E}_{\boldsymbol{0}} \boldsymbol{E}_{\min }$ \\
\cline { 2 - 7 } & $\mathrm{U}_{1}$ & 27,5 & 97,0 & 0,0 & infinity & infinity \\
\cline { 2 - 7 } & $\mathrm{U}_{2}$ & 65,8 & 132,1 & 18,9 & 7,0 & 3,5 \\
\cline { 2 - 7 } & $\mathrm{U}_{3}$ & 99,8 & 152,8 & 63,4 & 2,4 & 1,6 \\
\cline { 2 - 7 } & $\mathrm{U}_{4}$ & 128,9 & 183,4 & 93,1 & 2,0 & 1,4 \\
\cline { 2 - 7 } & $\mathrm{V}_{1}$ & 53,8 & 120,7 & 10,3 & 11,7 & 5,2 \\
\cline { 2 - 7 } & $\mathrm{V}_{2}$ & 74,3 & 138,5 & 27,8 & 5,0 & 2,7 \\
\hline & $\mathrm{V}_{3}$ & 116,3 & 168,5 & 77,0 & 2,2 & 1,5 \\
\hline experiment & $\mathrm{V}_{4}$ & 126,8 & 182,1 & 89,8 & 2,0 & 1,4 \\
\hline
\end{tabular}

Accordingly to the results it can be concluded that, firstly, by using rotor structure based on the $U_{1}$ concept it is possible to build the ECPMS-machine with field-weakening control of no-load infinite speed drive. Secondly, in the $\mathrm{U}_{2}$ and $\mathrm{V}_{1}$ concepts it has been managed to decrease the stator flux linkage three times at least.

Thanks to presented results it has been decided that the next work will focus on experimental validation of the ECPMS machine with a rotor prototype based on the $V_{1}$ concept.
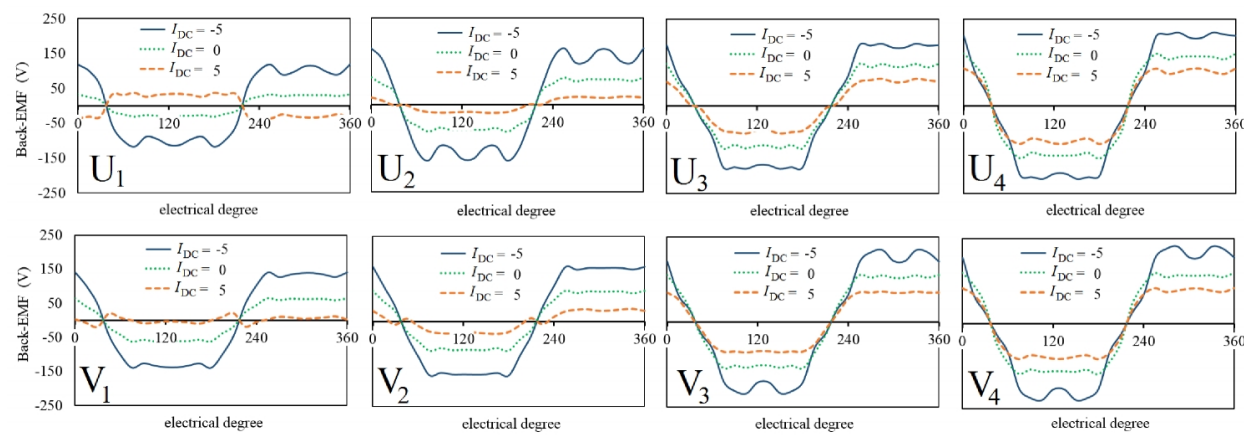

Fig. 4. 3D-FEA predictions of back-EMF waveforms under $I_{\mathrm{DC}}=-5,0,5 \mathrm{~A}$ at $1000 \mathrm{rpm}$ constant speed.
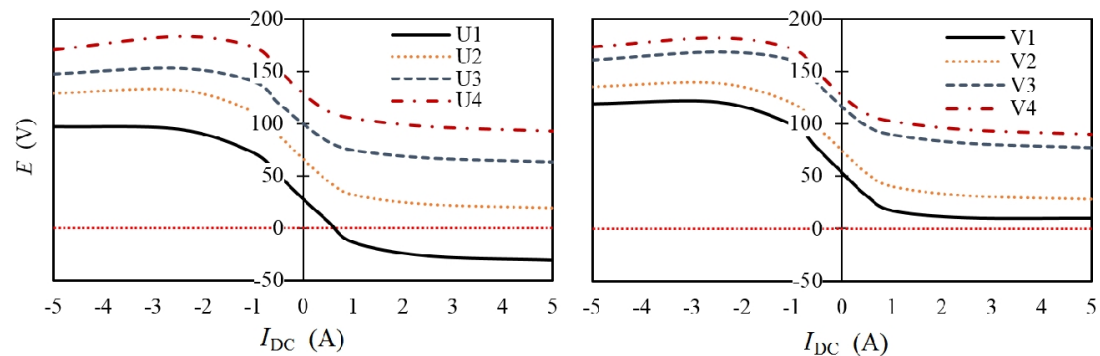

Fig. 5. Characteristics of no-load output terminal voltage $E_{0}$ vs. IDC. 
Figure 6(a) presents additional FEA predictions of the cogging torque in flux weakening operation. The results show that the impact of the control coil current on maximum value of cogging torque is neglected. A quite different situation is observed in flux strengthening operation

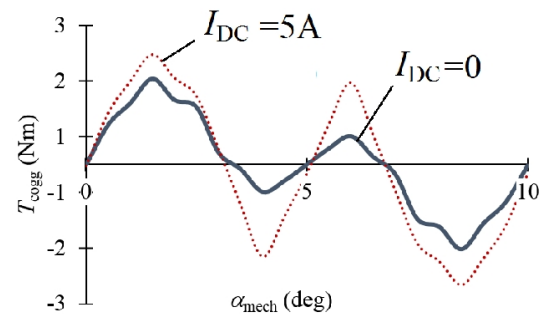

(Fig. 6(b), Fig. 7)

Figure 8 shows the FEA predictions of torque vs. rotor position at normal and full-load armature current $I_{\mathrm{s}}=1 . .3 \cdot I_{\mathrm{SN}}$ without the control coil current $I_{\mathrm{DC}}=0$ (Fig. 8(a)) and under field-strengthening conditions at $I_{\mathrm{DC}}=-5 \mathrm{~A}$ (Fig. 8(b)).

Fig. 6. FEA predictions of the cogging torque for $\mathrm{V}_{1}$ concept at no-load and weakening (a) and strengthening operation (b).

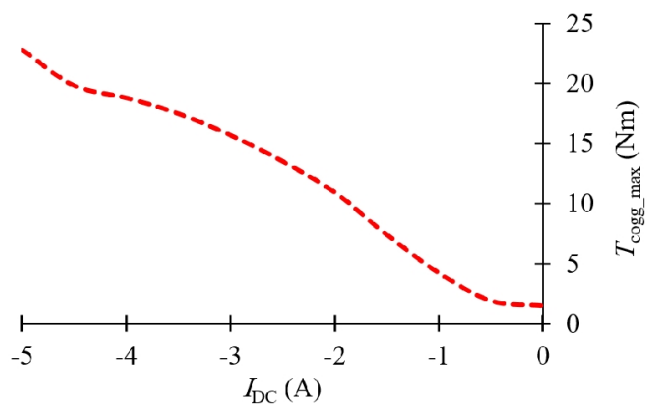

Fig. 7. FEA predictions of maximum value of the cogging torque versus DC control coil current in flux strengthening operation

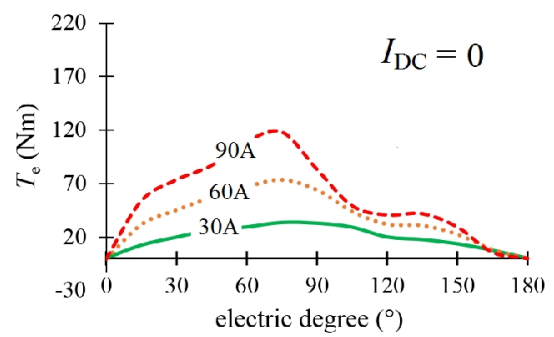

a)

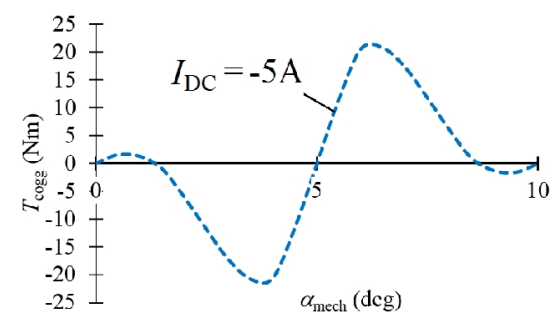

b)

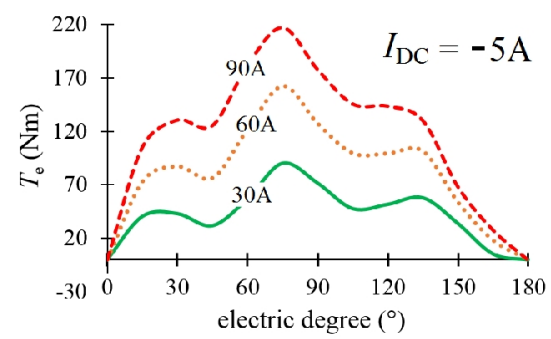

b)

Fig. 8. FEA predictions of the electromagnetic torque for $\mathrm{V}_{1}$ concept without DC excitation field (a) and at strengthening operation (b)

Characteristics show that a start torque of the machine up $220 \mathrm{Nm}$ can be successfully obtained under strengthening operation at $I_{\mathrm{s}}=3 \cdot I_{\mathrm{sN}}=60 \mathrm{~A}$. Unfortunately, when this mode occurs, as can be observed in the Fig. 6(b), the largest cogging torque is performed and its $T_{\text {cogg_max_FEA } \%}$ is doubled and amounted about $10 \%$.

\section{EXPERIMENTAL RESULTS}

Figure 9 shows photos of the rotor magnetic structure based on the $V_{1}$ concept. In Fig. 9(a) there can be seen a lamination with an unique multiple flux barrier arrangement with: 1 piece of SFB, 3 pieces of EFB and 2 pieces of RFB per one pole of the machine. Figure 9(b) shows one of two magnetic parts of the rotor with 10 pieces of magnets per one pole. The assembled rotor prototype named ECPMSM $\mathrm{V} 1$ is illustrated in Fig. 9(c).

The lamination used in the prototype was a $0.5 \mathrm{~mm}$ thick steel sheet of M400-50A. The PMs (N38SH) have remanent a flux density of $1.23 \mathrm{~T}$ and coercive force of $907 \mathrm{kA} / \mathrm{m}$.

As can be seen in the Fig. 9(b) the PMs are filled into two EFB and each RFB barriers. One open EFB barrier (without $\mathrm{PM}$ ) is located closest to the axis of the machine.

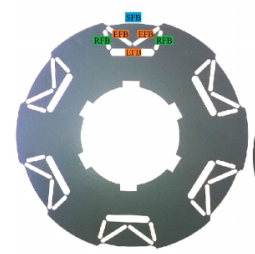

a)

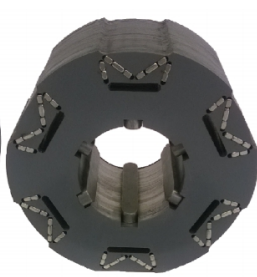

b)

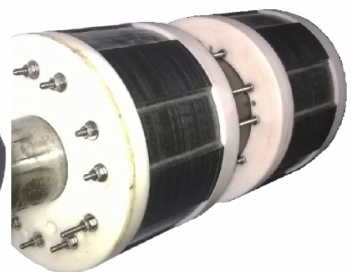

c)
Fig. 9. Photos of rotor lamination (a) one part of the rotor with PMs (b) and assembled rotor $(\mathrm{c})$.

TABLE III. MACHINE DESIGN DATA AND REQUIREMENTS

\begin{tabular}{|c|c|c|}
\hline Parameter & value & Unit \\
\hline Rotor outer diameter, $D_{r}$ & 163 & $\mathrm{~mm}$ \\
\hline Stator stack length, $l_{s}$ & $2 \times 80$ & $\mathrm{~mm}$ \\
\hline Range of control coil current, $I_{\mathrm{DC}}$ & \pm 5 & $\mathrm{~A}$ \\
\hline Voltage reduction ratio, $\Delta U_{0}$ & $1: 4$ at least & - \\
\hline Supply voltage & 300 & VDC \\
\hline Nominal stator current, $I_{s} \mathrm{~N}$ & 30.0 & $\mathrm{~A}(\mathrm{rms})$ \\
\hline Stator phase resistance, $R_{S}$ & 0.2 & $\Omega$ \\
\hline DC coil resistance, $R_{D C}$ & 8.4 & $\Omega$ \\
\hline Speed range, $n_{\max }$ & 8000 & $\mathrm{~min}^{-1}$ \\
\hline Maximal torque, $T_{\max }$ & 120 & $\mathrm{Nm}$ \\
\hline Pair-poles, $p$ & 6 & - \\
\hline
\end{tabular}


The main design data for machine prototype based on the $\mathrm{V}_{1}$ concept are depicted in Table III.

A motor prototype has been manufactured and set on an experimental setup (Fig. 10) which consists of (apart from the ECPMSM V1 machine) load/drive induction machine (IM) ABB CM-5-7, and torque meter (TM) Dataflex 32/100, also with hidden digital oscilloscope Tektronix DPO7054.

It should be mentioned that presented machine has divided stator cores made by two standard six-pole 36-slots lamination stacks with a double-layer, one-slot chorded winding.

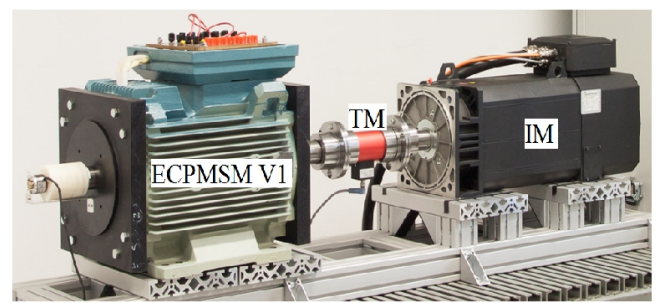

Fig. 10. Experimental setup for testing ECPMSM V1 prototype.

In order to confirm the effectiveness of the field weakening and strengthening capability of the prototype machine experiments testing the back-EMF waveforms at different values of the control coil current $I_{\mathrm{DC}}$ have been carried out. Figure 11 shows the no-load back-EMF waveforms performed at $1000 \mathrm{rpm}$ constant speed under three different current excitation levels: in flux strengthening (Fig. 11(a)), no-load (Fig. 11(b)) and in flux weakening (Fig. 11(c)).

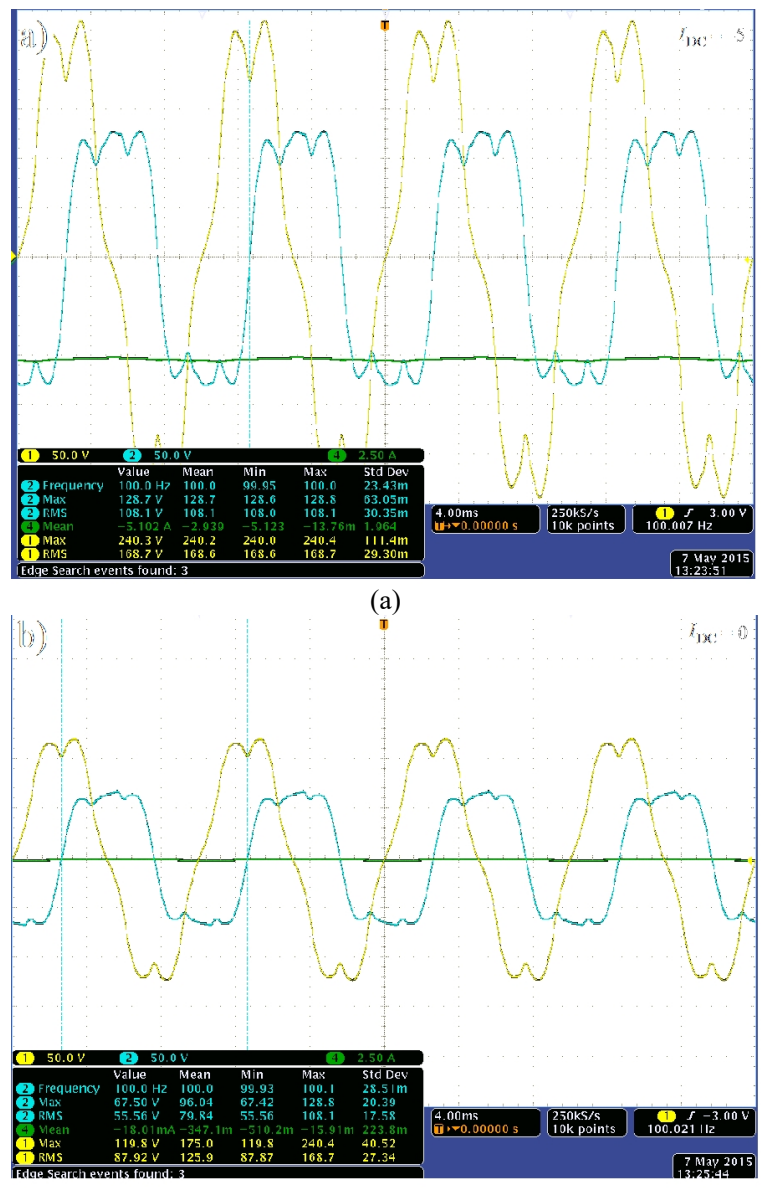

(b)

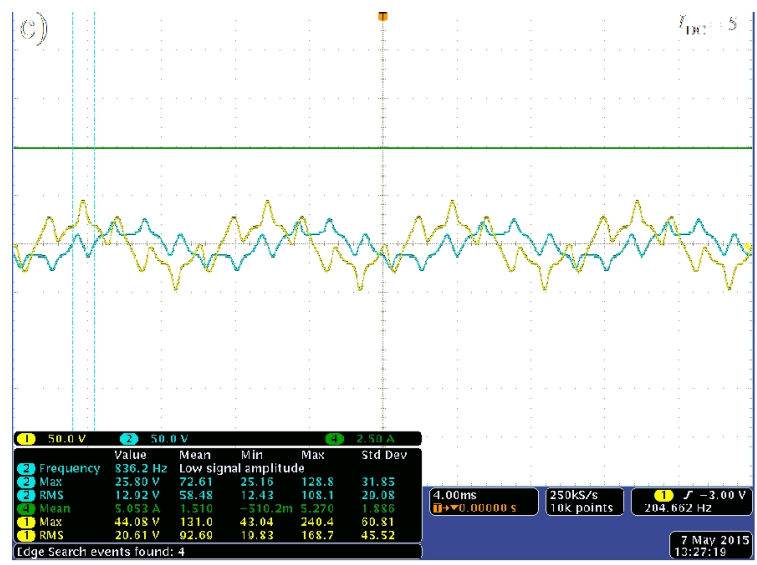

(c)

Fig. 11. Waveforms of Back-EMF phase (cyan) and phase-to-phase (yellow) waveforms at $1000 \mathrm{rpm}$ for three selected DC control coil current: $-5 \mathrm{~A}$ (a); 0 (b) and $5 \mathrm{~A}(\mathrm{c})$.

In Table II additionally results of back-EMF values measured on the ECPMSM V1 prototype are shown.

Figure 12 shows the field control capability of the prototype machine. The measured no-load output terminal voltage characteristic in $I_{\mathrm{DC}}$ function is presented for the machine speed of $1000 \mathrm{rpm}$.

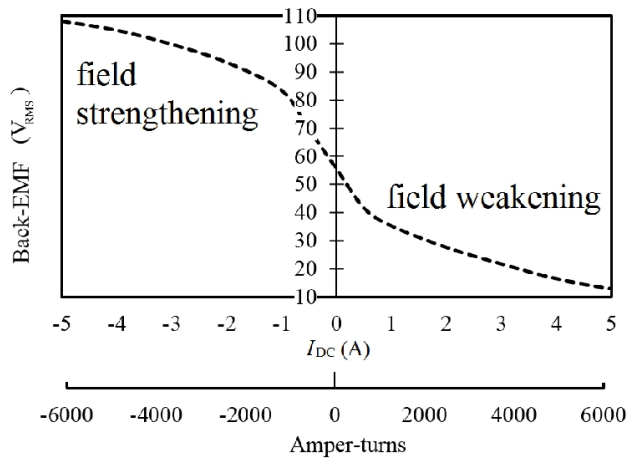

Fig. 12. Characteristic of no-load output terminal voltage $E_{0}$ in function $I_{\text {DC }}$ - experimental results.

\section{CONCLUSIONS}

The aim of this paper was to develop and indicate a magnetic rotor structure for the modified ECPMS machine with high field-weakening and strengthening possibility.

Three different rotor design concepts have been researched and analysed by using the 3D-FEA to overcome

the influence of magnets and flux barriers arrangement on controlling field excitation, and their features, field control capabilities and limitations.

The obtained results confirm that presented rotor structures allow developed ECPMS-machines with excellent field-weakening control for adjustable speed drive applications.

Particular attention has been paid to a rotor design based on a concept with six flux-barrier arrangement. The concept has been used in the ECPMSM V1 machine prototype and successfully tested. The experimental results have shown that the field control ratio of the machine equal to $10: 1$ has been effectively obtained in the prototype which implying its great application potential in the development of the BEV of other adjustable speed drive technology. 


\section{REFERENCES}

[1] Y. Amara, S. Hlioui, R. Belfkira, G. Barakat, M. Gabsi, "Comparison of open circuit flux control capability of a series double excitation machine and a parallel double excitation machine", IEEE Trans. on Vehicular Technology, vol. 60, no. 9, pp. 4194-4207, 2011. [Online]. Available: https://doi.org/10.1109/TVT.2011.2173704

[2] T. A. Lipo, M. Aydin, "Field weakening of permanent magnet machines - design approaches", Research Report 2004-13, Confidential, 2004.

[3] Yu Wang, Zhiquan Deng, "Hybrid excitation topologies and control strategies of stator permanent magnet machines for DC power system", IEEE Trans. on Industrial Electronics, vol. 59, no. 12, pp. 4601-4616, 2012. [Online]. Available: https://doi.org/10.1109/ TIE.2012.2183842

[4] Y. Amara, L. Vido, M. Gabsi, et al., "Hybrid excitation synchronous machines: energy-efficient solution for vehicles propulsion", IEEE Trans. Vehicular Technology, vol. 58, no. 5, pp. 2137-2149, 2009. [Online]. Available: https://doi.org/10.1109/TVT.2008.2009306

[5] M. Wardach, "Hybrid excited claw pole electric machine", Int. Conf. Methods and Models in Automation and Robotics (MMAR), Miedzyzdroje, Poland, 2016, pp. 152-156, [Online]. Available: https://doi.org/10.1109/MMAR.2016.7575124

[6] J. Gieras, "PM synchronous generators with hybrid excitation systems and voltage control capabilities", XX Int. Conf. Electrical Machines (ICEM), Marseille, 2012, pp. 2573-2579, [Online]. Available: https://doi.org/10.1109/ICElMach.2012.6350248

[7] A. A. Afinowi, Z. Q. Zhu1, Y. Guan, J. C. Mipo, P. Farah, "Hybridexcited doubly salient synchronous machine with permanent magnets between adjacent salient stator poles", IEEE Trans. on Magnetics, vol. 51, no. 10, 2015. [Online]. Available: https://doi.org/ 10.1109/TMAG.2015.2446951

[8] H. Woehl-Bruhn, W.-R. Canders, N. Domann, "Classification of field-weakening solutions and novel PM machine with adjustable excitation", XIX Int. Conf. Electrical Machines (ICEM), Rome, 2010. [Online]. Available: https://doi.org/10.1109/ICELMACH.2010. 5608323

[9] H. May, R. Palka, P. Paplicki, S. Szkolny, M. Wardach, "Comparative research of different structures of a permanent-magnet excited synchronous machine for electric vehicles", Electrical Review, no. 88, vol. 12a, 2012, pp. 53-55.

[10] J. A. Tapia, F. Leonardi, T. A. Lipo, "Consequent-pole permanentmagnet machine with extended field-weakening capability", IEEE
Trans. Industry Applications, vol. 39, pp. 1704-1709, 2003 [Online]. Available: https://doi.org/10.1109/TIA.2003.818993

[11] P. Paplicki, R. Piotuch, "Improved control system of pm machine with extended field control capability for EV drive", Ideas for Industrial Application, vol. 317, pp. 125-132, 2015. [Online]. Available: https://doi.org/10.1007/978-3-319-10990-9 12

[12] M. Bonislawski, R. Palka, P. Paplicki, M. Wardach, "Ünconventional control system of hybrid excited synchronous machine", $20^{\text {th }}$ Int. Conf. Methods and Models in Automation and Robotics (MMAR), 2015. [Online]. Available: https://doi.org/10.1109/MMAR 2015.7283951.

[13] P. Paplicki, M. Wardach, M. Bonislawski, R. Palka, "Simulation and experimental results of hybrid electric machine with a novel flux control strategy", Archives of Electrical Engineering, vol. 64, no. 1, pp. 37-51, 2015. [Online]. Available: https://doi.org/10.1515/aee2015-0005

[14] P. Di Barba, M. Bonislawski, R. Palka, P. Paplicki, M. Wardach, "Design of hybrid excited synchronous machine for electrical vehicles", IEEE Trans. Magn., vol. 51, no. 8, 2015. [Online]. Available: https://doi.org/10.1109/TMAG.2015.2424392

[15] P. Putek, P. Paplicki, R. Palka, "Low cogging torque design of permanent-magnet machine using modified multi-level set method with total variation regularization", IEEE Trans. Magn., vol. 50, no. 2, 2014. [Online]. Available: https://doi.org/10.1109/ TMAG.2013.2286297

[16] P. Putek, P. Paplicki, M. Slodicka, et al, "Application of topological gradient and continuum sensitivity analysis to the multi-objective design optimization of a permanent-magnet excited synchronous machine", Electrical Review, vol. 88, no. 7a, pp. 256-260, 2012.

[17] P. Putek, P. Paplicki, R. Palka, "Topology optimization of rotor poles in a permanent-magnet machine using level set method and continuum design sensitivity analysis", Compel, The International Journal for Computation and Mathematics in Electrical and Electronic Engineering, vol. 33, no. 3, pp. 711-728, 2014. [Online]. Available: http://dx.doi.org/ 10.1108/COMPEL-09-2013-0286.

[18] M. Wardach, "Cogging torque reducing in electric machine by poling modification of magnetic circuit", Electrical Review, vol. 85, no. 2, pp. 131-133, 2009.

[19] P. Paplicki, "Design optimization of the electrically controlled permanent magnet excited synchronous machine to improve flux control range", Electronika ir Electrotechnika, vol. 20, no. 10, pp. 17-22, 2014. [Online]. Available: http://dx.doi.org/10.5755 /j01.eee.20.10.5934 